\title{
Gestão das políticas públicas do Ministério do Esporte do Brasil
}

CDD. 20.ed. 796.06

http://dx.doi.org/10.1590/1807-55092015000100065

\author{
Dirceu Santos SILVA* \\ Carlos Nazareno Ferreira BORGES ${ }^{* *}$ \\ Silvia Cristina Franco AMARAL*
}

*Faculdade de Educação Física, Universidade Estadual de Campinas.

${ }^{* *}$ Centro de Educação Física e Desportos, Universidade Federal

do Espírito Santo.

\section{Resumo}

0 objetivo deste artigo foi analisar e discutir as ações políticas do Ministério do Esporte para as áreas do esporte e do lazer. Para tanto, foi realizada uma pesquisa documental, seguida de uma análise de conteúdo das leis e documentos que regem as políticas do Ministério do Esporte. Emergiram três categorias centrais dessa análise: modelo de gestão, concepção de direito social e canais de participação. Os resultados indicaram que as ações políticas se aproximaram da gestão pública gerencial, e compreende os direitos sociais como serviços a serem prestados pelo Estado. Além disso, a participação da sociedade civil só ocorreu de forma institucionalizada, por meio do Conselho Nacional de Esporte e das Conferências Nacionais do Esporte (CNEs). Ambiguamente, foram também identificadas ações que promoviam uma visão societal, que ampliou o entendimento do lazer e o afirmou como um direito social, mas que nos últimos anos estão subsumidas pela visão gerencial.

PALAVRAS-CHAVE: Lazer; Esporte; Direitos sociais; Participação.

\section{Introdução}

As discussôes sobre as políticas públicas de esporte e de lazer, no Brasil, têm ganhado ênfase no campo científico/acadêmico da Educaçáo Física. Essa temática começou a ganhar força a partir da Constituição Federal Brasileira de 1988, quando o lazer passou a ser contemplado como direito social e o esporte como setor estratégico, de direito individual, a ser incentivado pelo Estado ${ }^{1}$, o que influenciou na disseminação da produção teórica sobre o assunto.

Esse período de alargamento da democracia, dos anos de 1980, e o avanço das questóes sociais foram defrontados pela nova tendência global neoliberal, que ganhou evidência, no Brasil, a partir do ano de 1989, no governo de Fernando Collor de Mello. A consolidação desse modelo foi verificada com a Reforma do Estado no ano de 1995, com a criação do Ministério da Administração e Reforma do Estado (MARE), o que contrapóe o projeto democratizante da sociedade civil na garantia dos direitos sociais, como o lazer, a saúde, a educação, a segurança, dentre outros ${ }^{2}$.

No ano de 2003, com a criaçáo do Ministério do Esporte, o setor ganhou "status" de pasta única governamental, o que proporcionou a criaçáo de novas ações políticas. No campo do lazer, destacou-se a criação do
Programa Esporte e Lazer da Cidade (PELC), iniciado 2003 e implementado em 2004, que estabeleceu um novo perfil de política com o intuito de garantir o lazer como direito social, conforme descrição do programa $^{3}$. Merece destaque ainda, o Programa Segundo Tempo (PST), implementado em 2003, que se configurou como uma das principais açóes do Ministério do Esporte, na área social. Os dois programas são justificados como açôes políticas estratégicas para superar a desigualdade, e ambos são focalizados em áreas de vulnerabilidade social ${ }^{2}$.

Em 2013, o Ministério do Esporte completou uma década de existência, e ao longo desses anos, o setor despertou o interesse de diversas pesquisas. Destacam-se os temas como: a concepçáo dos gestores acerca do esporte e do lazer ; $^{4}$ a construçáo de espaços e equipamentos, a formação dos agentes sociais ${ }^{5}$; e o acesso restrito ao lazer $^{3}$. Além desses temas, surgiram novas demandas, com destaque para os estudos relacionados às novas formas de gestão pública, como a intersetorialidade $e^{6-7}$ e a agenda dos megaeventos esportivos ${ }^{8-9}$.

A partir desse contexto, o presente estudo buscou responder as seguintes questóes: como tem sido planejada e desenvolvida a gestão das políticas públicas de esporte 
e lazer pelo Ministério do Esporte, no Brasil? Quais são os avanços e limites das ações políticas em torno da legitimação destes campos como direitos sociais?

\section{Método}

Trata-se de uma pesquisa documental, com abordagem qualitativa, que procurou significados e características situacionais dos documentos analisados, o que possibilitou uma leitura institucional acerca da gestão das políticas públicas do Ministério do Esporte $^{10}$.

Como procedimento metodológico foi realizado um levantamento e uma análise dos principais documentos coletados no "website" do Ministério do Esporte, entre o período de 2003 a 2012, com destaque para o planejamento, leis que regem a instituição, programas, projetos, organograma, orçamentos e relatórios das Conferências Nacionais do Esporte (CNEs).

Os documentos foram coletados por meio de um busca no "website" do Ministério do Esporte, e buscou contemplar diversos programas e características da gestão. Após uma busca, os documentos analisados foram: Esporte na Escola; Projetos Esportivos Sociais; Documento final da I CNE; Documento final da II CNE; Texto básico da III CNE; Dossiê de candidatura do Rio 2016; Manual para elaboração de projetos de implantação para construção das Praças da Juventude; Organograma do Ministério do Esporte; Diretrizes do Programa Segundo Tempo 2011; Balanço da Copa Mundo Fédération Internationale de Football Association (FIFA) de 2014; Diretrizes do Programa Esporte e Lazer da Cidade; Manual do programa Pintando a Liberdade; Manual

\section{Resultados e discussão}

Para organização do artigo, foi realizada a inferência das açôes políticas, a partir das três categorias de análise que emergiram do tratamento dos dados: gestão pública; concepção de direito social; e participação da sociedade civil.

\section{Modelo de gestão pública do Ministério do Esporte: gerencial e societal}

A criação do Ministério do Esporte ocorreu no governo do presidente Luiz Inácio Lula da Silva, ao separar as pastas do turismo e do esporte a partir da
O objetivo desse estudo foi analisar e discutir as açôes políticas do Ministério do Esporte para as áreas do esporte e do lazer.

do programa Pintando a Cidadania; Jogos dos Povos Indígenas; Rede Cedes; e Prêmio Brasil de Esporte e Lazer de Inclusão Social.

Além disso, foram selecionados para a análise os seguintes documentos que regulam as açóes do Ministério do Esporte: Portaria n. 221, de 1 de outubro de 2002; Lei n. 10.683, de 28 de maio de 2003; Decreto n. 4.668, de 9 abril de 2003; Lei n. 10.671, de 15 de maio de 2003; Lei n. 10.891, de 9 de julho de 2004; Lei n. 11.345, de 14 de setembro de 2006; Lei n. 11.438, de 29 de dezembro de 2006; Decreto n. 7.529, de 21 julho de 2011; Decreto n. 7.529, de 21 julho de 2011; Decreto n. 7.784, de 7 de agosto de 2012; Lei n. 12.663, de 5 de junho de 2012. Esses documentos e leis foram coletados no "website" do Ministério do Esporte e da Presidência da República.

A técnica utilizada para tabulação e interpretaçáo dos dados foi à análise de conteúdo, que permitiu o recorte dos textos de acordo com os conteúdos mais significativos, para a posterior categorização. As fases da análise de conteúdo foram organizadas em três polos cronológicos: a pré-análise, que teve como objetivo tornar operacionais e sistematizar as ideias iniciais, ler e escolher a documentação; a exploração do material, que correspondeu à fase de aprofundamento na leitura e análise; e o tratamento dos resultados, a categorização, a inferência e a interpretação ${ }^{11}$.

Medida Provisória n. 103, de 1 de janeiro de 2003. No entanto, a Medida Provisória foi substituída pela Lei n. 10.683, de 28 de maio de 2003, que organizou o Ministério do Esporte. As competências do Ministério do Esporte desde a sua criação são: a) desenvolvimento de uma política nacional do esporte; b) intercâmbio com organismos públicos e privados, nacionais e internacionais; c) estímulo às iniciativas públicas e privadas; e d) planejamento, coordenação e avaliação dos planos e programas de incentivo aos esportes e às açôes de democratização e inclusão social ${ }^{12}$. 
A partir do decreto n. 4.668, de 9 de abril de 2003, o Ministério do Esporte foi estruturado em quatro secretarias: Secretaria Nacional de Esporte Educacional; Secretaria Nacional de Desenvolvimento de Esporte e Lazer; Secretaria Nacional de Esporte de Alto Rendimento; e Secretaria Executiva ${ }^{13}$.

O Ministério do Esporte e as três secretarias foram entregues ao Partido Comunista do Brasil (PCdoB): a Secretaria Nacional de Alto Rendimento, a Secretaria Nacional de Esporte Educacional e a Secretaria Executiva. A escolha do PCdoB de acordo com Castellan ${ }^{14}$ foi uma troca de favores políticos, já que esse partido não tinha uma discussão acumulada sobre a temática, mas desde a década de 80 apoiou o Partido dos Trabalhadores $(\mathrm{PT})$ a chegar à presidência. A Secretaria Nacional de Desenvolvimento de Esporte e Lazer foi ocupada por quadros do PT, e contou com pessoas da área acadêmica da Educação Física e do Lazer. $\mathrm{O}$ PT possuía uma setorial nacional de esporte e lazer fundada em 1998 e desde 1992 já discutia o tema por meio dos cadernos "O Modo Petista de Governar". No entanto, essa ocupação do PT só ocorreu até o início de 2006, de forma isolada, em uma única secretaria do Ministério.

Das quatro secretarias, três levaram em consideração a concepção clássica de esporte proposta no Manifesto Mundial do Esporte no ano de 1964 e discutida no Brasil por Tubino ${ }^{15}$, que envolve o esporte educacional, o esporte de participaçáo e o esporte de alto rendimento. A divisão do Ministério do Esporte por secretarias definiu as responsabilidades e políticas de cada setor. No entanto, a partir do Decreto n. 7.529, de 21 julho de 2011, foram reestruturados os cargos do Ministério, com alteraçóes no seu organograma. Duas secretarias foram mantidas na atual configuração da instituição, a Secretaria Executiva e a Secretaria Nacional de Esporte de Alto Rendimento; enquanto duas secretarias foram mescladas, a Secretaria Nacional de Esporte Educacional e a Secretaria Nacional de Desenvolvimento de Esporte e Lazer, sendo criada a Secretaria Nacional de Esporte, Educação, Lazer e Inclusão Social. Outra novidade na estrutura do Ministério do Esporte foi à criação da Secretaria Nacional de Futebol e Defesa dos Direitos do Torcedor ${ }^{16-17}$.

A Secretaria Executiva tem como objetivo supervisionar e coordenar as atividades dos sistemas federais, planejamento, orçamento e inovação institucional. As principais ações políticas da instituição são: CNEs; Lei de Incentivo ao Esporte; Praça da Juventude; e Praças do Programa de Aceleraçáo do Crescimento (PAC) ${ }^{18}$, posteriormente denominadas de CEU's - Centro de Artes e Esportes Unificados.
A Secretaria Nacional de Esporte de Alto Rendimento (SNEAR) tem a função de coordenar, formular e implementar políticas relativas ao esporte de competição e implementação das diretrizes do Plano Nacional do Esporte. As principais políticas da secretaria são: Programa Descoberta do Talento Esportivo; Programa Bolsa Atleta; Rede CENESP (Centro de Excelência Esportiva); Jogos Olímpicos Rio 2016; e Jogos Escolares Brasileiros ${ }^{18}$.

A Secretaria Nacional de Esporte, Educação, Lazer e Inclusão Social (SNEELIS) tem como objetivo implantar as diretrizes relativas ao Plano Nacional de Esporte, bem como o desenvolvimento da prática esportiva no âmbito do sistema de ensino e do esporte de participação (como forma de lazer). As principais políticas são: PELC; PST; Programa Segundo Tempo no Mais Educação (Esporte da Escola); Programa Pintando a Liberdade ${ }^{\mathrm{b}}$; Programa Pintando a Cidadaniac; Jogos dos Povos Indígenas ${ }^{\mathrm{d}}$; Rede Cedes (Centro de Desenvolvimento do Esporte Recreativo e do Lazer); Cedime (Centro de Documentaçáo e Informação do Ministério do Esporte); e o Prêmio Brasil de Esporte e Lazer de Inclusão Social ${ }^{16,18}$.

A Secretaria Nacional de Futebol e Defesa dos Direitos do Torcedor (SNFDDT) tem como objetivo contribuir para o melhoramento do futebol no Brasil, bem como fiscalizar cumprimento da legislação esportiva e do Estatuto de Defesa do Torcedor. As principais políticas da instituição são: Projeto Copa do Mundo FIFA 2014; Timemania; e Torcida Legal ${ }^{16,18}$.

A criaçáo de uma secretaria específica para tratar o futebol como acréscimo da SNEAR sinaliza que a atual intenção do Ministério do Esporte é priorizar apenas um modelo de prática esportiva. Os realces se confirmam com a focalização dos recursos para o esporte de alto rendimento, como podem ser encontradas no portal Siga Brasil, do Senado Federal, do qual foram coletados os orçamentos previstos para os anos de 2004, 2011, 2012 e 2013. Nos anos coletados foi constatado um crescimento expressivo do orçamento para os programas do Ministério do Esporte, sobretudo do ano de 2004 para o de 2011, quando o orçamento total passou de $\mathrm{R} \$$ 358.201.298 para $\mathrm{R} \$ 2.470 .406 .497$, e aumentou ainda mais em 2012 para $\mathrm{R} \$ 2.617 .848 .045 \mathrm{e} \mathrm{em}$ 2013 para $\mathrm{R} \$ 3.382 .609 .335^{19}$.

Apesar do aumento do orçamento total do Ministério do Esporte, ficou evidente que esse orçamento foi direcionado para o esporte de rendimento, sobretudo para o Programa Esporte e Grandes Eventos Esportivos, que foi criado em 2012, e concentrou $\mathrm{R} \$ 2.278 .383 .576$, dos $\mathrm{R} \$ 2.617 .848 .045$ do orçamento previsto para o 
ano e R 3 3.067.576.386 dos R 3 382.609.335 do orçamento previsto para o ano de $2013^{19}$.

Dessa forma, ficou evidente que o incentivo ao esporte educacional e de participação foram minimizados ou quase extintos em detrimento do esporte de alto rendimento, sendo acrescido pela exclusão do PELC e do Programa Inclusão Social pelo Esporte, do orçamento previsto para o ano de 2012 e 2013.

O novo formato do Ministério do Esporte pode ser justificado pela atual agenda política, à medida que o País tem como desafio realizar os principais megaeventos esportivos, a Copa do Mundo FIFA 2014 já realizada e os Jogos Olímpicos Rio 2016. Ao priorizar o esporte de alto rendimento, a instituição subsumiu a proposta da Constituição Federal Brasileira de 1988, de garantia do lazer como direito social e prioridade de promoçáo do esporte educacional, conforme inciso II, do artigo $217^{1}$.

Ao analisarmos os documentos do Ministério do Esporte, um primeiro aspecto que nos chamou a atenção esteve relacionado à concepção de gestão pública, que a pasta assumiu paulatinamente na condução das políticas de esporte e de lazer. Para essa análise tomamos a discussão realizada por PAU$\mathrm{LA}^{20}$, quando afirmou a existência de dois modelos de gestão pública que surgiram no Brasil após a redemocratização: o gerencial e o societal.

O modelo de gestáo pública gerencial teve início nos anos de 1980, com base nas experiências inglesa e estadunidense. Esse projeto político alinhou-se às recomendaçóes dos organismos multilaterais internacionais de reforma do Estado (Banco Mundial e Fundo Monetário Internacional) com foco no desenvolvimento das dimensóes econômico-financeira e institucional-administrativa. O modelo gerencial tem como objetivo melhorar as decisóes estratégicas do governo por meio da descentralização e bom funcionamento do mercado ${ }^{20}$.

A gestão pública societal tem raízes nos movimentos sociais brasileiros, dos anos de 1960, com ideais voltadas para redemocratização na luta contra a ditadura. O projeto político enfatiza a participação da sociedade civil e tem como base a dimensão sociopolítica, ou seja, a melhoria nas condiçōes de vida de todos os cidadãos. Ambos os modelos são considerados as novas formas de gestão pública ${ }^{20}$.

No primeiro mandato do governo de Luiz Inácio Lula da Silva, no Ministério do Esporte, foi criada a Secretaria Nacional de Desenvolvimento do Esporte e Lazer (SNDEL) com uma tendência à garantia do esporte-participaçáo e do lazer em seu sentido mais amplo ${ }^{\text {e }}$ A criação do PELC aponta para essa tendência, a partir do momento que o programa tinha como objetivo inicial: "suprir a carência de políticas públicas e sociais que atendam às crescentes necessidades e demandas da população por esporte recreativo e lazer, sobretudo daquelas em situaçôes de vulnerabilidade social e econômica"21.

O PELC foi pensado no Plano Plurianual (20042007) do Ministério do Esporte. O programa rompe com o modelo de gestáo pública de esporte e lazer que objetivava o "rendimento" hegemonicamente desde a criação do Decreto n. 3.199, de 14 de abril de $1941^{3}$.

No contexto atual, as diretrizes do PELC são: autoorganização da comunidade; trabalho coletivo; intergeracionalidade; fomento e difusão da cultura local; respeito à diversidade; intersetorialidade; e autogestão. Além disso, o programa prevê a formação de maneira modular: I Módulo Introdutório, que deve acontecer até o quarto mês de execução do convênio, sendo central para a formaçáo e acontece por meio de uma carga horária de 32 horas; II Módulo de Aprofundamento/ Formação em Serviço, que deve ocorrer em todo o período de duração do convênio, com reunióes, no mínimo quinzenais, para estudo, troca de experiências, planejamento, palestras e oficinas; e III Módulo de Avaliação, que compreende duas etapas: Avaliação I (AVI), da qual ocorre no $11^{\circ}$ mês do convênio, e AV II, da qual ocorre no $17^{\circ}$ mês do convênio ${ }^{22}$.

Até o ano de 2011, o PELC/Pronasci $i^{\mathrm{f}}$ buscava a focalização das açôes do Estado no que se refere ao esporte e ao lazer, conforme trechos da "Coleção de Política Intersetorial: PELC e Pronasci” lançada pelo Ministério do Esporte, quando foi abordado que o programa foi:

[...] implementado através de funcionamento de núcleos de esporte recreativo e de lazer, para jovens entre 15 e 24 anos, suas famílias e comunidades, que vivem em situaçôes de vulnerabilidade social e econômica, reforçados das condiçōes de injustiças, violências e exclusão social a que estão submetidas, com vistas a melhoria da qualidade de vida ${ }^{23}$.

Dessa forma, o PELC realizava uma gestão híbrida, com a democratização das práticas de lazer e a participação da sociedade civil, o que aproxima o programa de um modelo mais societal. Mas, ao propor a desresponsabilizaçáo do Estado na garantia universal dos direitos sociais, e focalizar suas açôes em áreas de vulnerabilidade social, coaduna-se com o modelo gerencial ${ }^{20}$. O programa busca a transferência de responsabilidades do Estado em direção à sociedade civil e como descrito no seu projeto "[...] é definido como prazo para que a comunidade local se aproprie desta tecnologia, com apoio estrutural e pedagógico 
do Ministério e, a partir daí, construa sua própria ação e possibilidades de financiamento" ${ }^{22}$. Ao se retirar do financiamento, o Governo Federal não tem desenvolvido a autonomia dos núcleos, mas sim, se retirando do processo, independente se o núcleo continuará ou não.

As características do PELC corroboram com que afirma DrAIBE ${ }^{24}$ acerca das políticas sociais em um ambiente de aprofundamento do projeto político neoliberal. A autora prevê três características centrais desse modelo de política: a privatização, a descentralização e a focalização. No PELC pode-se afirmar que a privatização ocorreu pelo deslocamento das obrigaçóes do Estado para o setor privado náo lucrativo, como associações filantrópicas e organizações comunitárias, no desengajamento do governo de algumas responsabilidades após o fim de cada convênio. A descentralização foi encarada como princípio de aumento da eficiência (menor relação custo-benefício para alcançar os objetivos, e buscou a otimização dos recursos utilizados) e da eficácia do gasto (relação comparativa entre os objetivos iniciais explícitos de um dado programa e os seus resultados finais alcançados). E a focalização foi perceptível com o direcionamento do gasto social a um público específico selecionado pela sua maior necessidade, isto é, em áreas de vulnerabilidade social e econômica, o que contrapóe a proposta de universalização dos direitos, condição primeira para o exercício de uma cidadania plena.

Em 2012, o PELC direcionou ainda mais o seu financiamento, a partir do momento que definiu como público-alvo três núcleos operacionais: Núcleos Todas as Idades, com o objetivo de ampliar açóes de democratização do acesso ao esporte e lazer; Núcleos para os Povos e Comunidades Tradicionais, com o objetivo de atender grupos culturalmente diferenciados e que se reconhecem como tal; e Núcleos Vida Saudável, com o objetivo de atender pessoas a partir de 45 anos e idosas (inclui também pessoas com deficiência). Esse modelo do programa aprofunda ainda mais a focalização ${ }^{22}$.

Identificou-se ainda no Ministério do Esporte, a Rede Cedes, o Cedime e o Prêmio Brasil de Esporte e Lazer de Inclusão Social como tentativas de aproximação com o modelo de gestão pública societal. Essas açóes buscam o desenvolvimento da dimensão sociopolítica, já que incentivam a produção de conhecimento e de iniciativas científicas, com ênfase no aperfeiçoamento e desenvolvimento das políticas públicas de esporte e lazer.

A Rede Cedes foi criada em 2003 e conta com um acervo amplo, no entanto, de acordo com STAREPRAVO et al. ${ }^{25}$ os campos político/burocrático e científico/acadêmico têm sido articulado de forma mínima, e pouco tem contribuído para o avanço nas gestóes estaduais e municipais.

A Rede Cedes integra ainda o PELC e articula com as Instituiçóes de Ensino Superior em busca da continuidade na produção e difusão de conhecimentos voltados para o aperfeiçoamento e qualificação de projetos, programas e políticas públicas ${ }^{26}$. Apesar dos avanços da Rede, em 2011 foi aberto um edital de chamada pública, com a intenção de fomentar pesquisas no campo do esporte e do lazer. No entanto, dos 42 projetos aprovados ${ }^{27}$ em todo o país por meio da Portaria n. 219, de 23 de dezembro de 2011, nem todos receberam o repasse financeiro do Ministério do Esporte, o que demonstra um enfraquecimento $\mathrm{da}$ atual rede e as incertezas de continuidade das açóes políticas de cunho social no país ${ }^{25}$.

A Rede Cedes articula ainda com o Cedime, (Centro de Documentação e Informação do Ministério do Esporte), com o objetivo de fomentar centros de memória e museus que têm a função de digitalização, catalogação, preservação, restauração, conservação e disponibilização dos acervos. Essa ação contribui para o desenvolvimento científico, tecnológico e pedagógico das políticas públicas ${ }^{26}$.

$\mathrm{Na}$ análise do Programa Prêmio Brasil de Esporte e Lazer de Inclusão Social também foi identificado uma aproximação com a gestão pública societal, pois seu objetivo foi reconhecer iniciativas científicas, pedagógicas, tecnológicas e jornalísticas que apresentam contribuiçóes para a qualificação das políticas públicas de esporte e lazer, com ênfase na dimensão sociopolítica e nas questóes de cunho social. São várias as categorias de premiação: Dissertação, Tese e Pesquisa Independente; Monografias de Graduação e Especialização; Relato de Experiência; e Ensaio e Mídias ${ }^{28}$.

Continuando a análise das açóes políticas do Ministério do Esporte, destacamos o PST, criado em 2003, como um dos principais programas com o objetivo de democratizar o acesso ao esporte educacional no contraturno escolar. O público-alvo são crianças, adolescentes e jovens entre seis e 17 anos de idade, prioritariamente matriculados na rede pública de ensino e em condiçóes de vulnerabilidade social ${ }^{29}$.

O PST tem como pauta a vivência, iniciação esportiva educacional, fomento ao esporte de base, prevendo um reforço alimentar, que pode ser um lanche ou um almoço. O programa deve ser executado de forma articulada, por meio de alianças e parcerias institucionais com entidades públicas e privadas sem fins lucrativos, que tenham mais de três anos de atuação na área. Os princípios do programa são: reversão do quadro de exclusão; compreensão do esporte e do lazer como 
direito de cada um e dever do Estado; universalizaçáo e inclusão social; e democratização da gestão ${ }^{29}$.

Com a atual agenda política do Ministério do Esporte, o PST não teve um orçamento previsto para o ano de 2013, mesmo sendo indicado como um dos principais programas da primeira gestão do setor. Um dos motivos que tem justificado o desaparecimento do PST está relacionado à sua integração com o Programa Mais Educação, vinculado ao MEC. O interesse do Estado no incentivo ao esporte de alto rendimento e na formação de atletas foi à prioridade em detrimento do fomento ao esporte educacional. Dessa forma, foi evidenciado que houve uma tentativa de aproximação de um modelo de gestão pública societal, sobretudo no primeiro mandado do Ministério do Esporte. No entanto, aos poucos esse modelo foi subsumido pelo financiamento e açóes em prol do esporte de alto rendimento e da nova agenda política dos megaeventos esportivos. $\mathrm{O}$ realce pode ser percebido no não repasse total de financiamento para a Rede Cedes e nos orçamentos previstos para os anos de 2012 e 2013, que contemplavam de forma minoritária o lazer ${ }^{19}$.

Ao prosseguirmos a análise das açóes políticas do Ministério do Esporte, notamos que a SNEAR tem como objetivo formar atletas para representarem o país em competiçóes internacionais, como percebidos no Programa Descoberta do Talento Esportivo, Jogos Escolares Brasileiros e Rede CENESP. Vale ressaltar que esse objetivo se perpetua desde 2003 e ganhou ênfase na atual fase das políticas públicas de esporte e lazer.

Das três ações políticas da SNEAR em destaque, duas compreendem a escola como espaço propício para detectar atletas. São elas: o Programa Descoberta do Talento Esportivo, que tem como objetivo identificar adolescentes e jovens na rede escolar, que tenham desempenho motor compatíveis com a prática do esporte de competiçáo, por meio de uma metodologia de avaliação, que conta com padróes técnicos testados por pesquisadores ${ }^{30}$; e os Jogos Escolares Brasileiros, que tem como objetivo promover a prática esportiva dos atletas matriculados na rede pública ou particular de ensino no Brasil, com o escopo de formação de atletas. Os jogos, no atual formato, incluí os Jogos da Juventudes, Olímpiadas Escolares ${ }^{\text {h }}$, Jogos Universitários Brasileiros (JUBs)i, dentre outros ${ }^{31}$.

O objetivo do projeto dos Jogos Escolares Brasileiros é promover o esporte de alto rendimento, apesar de ocorrer no ambiente escolar, o que corrobora com a pesquisa apresentada por BRACHT ${ }^{32}$, quando abordou que mesmo as atividades esportivas, em âmbito escolar, buscam atender ao esporte de alto rendimento.

Outra ação política em destaque na SNEAR foi a Rede CENESP (Centro de Excelência Esportiva), que tem como objetivo detectar e desenvolver talentos esportivos, por meio de um núcleo de desenvolvimento de pesquisa científica e tecnológica na área do esporte. A rede busca desenvolver talentos esportivos, e envolve o Ministério do Esporte, o COB e as Instituiçôes de Ensino Superior, o que aproximou do modelo de gestão pública gerencial ${ }^{20}$, ao centrar na dimensão econômico-financeira e busca de resultados.

$\mathrm{Na}$ SNEAR também foi possível verificar que o principal projeto da instituição tem sido os Jogos Olímpicos Rio 2016, que tem como objetivo deixar uma herança positiva para cidade do Rio de Janeiro. São três os cadernos de legados: Caderno de Legado Urbano, que reafirma a revitalizaçáo da zona portuária, regeneração das áreas do Maracanã, Engenhão e Sambódromo, e liga as diversas regiốes do Rio com o transporte de massa Bus Rapid Transit (BRTs); Caderno de Legado Social, que destaca o PST como meta para atingir três milhōes de jovens beneficiados até 2016; e Caderno Brasil, "Este é o País", que contém dados do Brasil e do Rio de Janeiro, e demonstra a economia nacional, consolidação da democracia, crescimento científico e tecnológico ${ }^{33}$.

Verificou-se que toda a estrutura do Ministério do Esporte foi modificada, com o intuito de atender o projeto dos Jogos Olímpicos Rio 2016, inclusive as açóes políticas de todas as secretarias. A preocupação do poder público, no atual contexto, tem enfatizado à formação de atletas, no entanto, apesar desse objetivo, o Brasil não conseguiu alcançar os resultados esperados nos Jogos Olímpicos Londres 2012, quando ficou na $22^{\circ}$ posição do quadro de medalhas, e a meta até os Jogos Olímpicos 2020 é ficar entre os 10 melhores países no quadro de medalhas.

Além disso, analisamos a SNFDDT, criada em 2010 a partir de um contexto de nova agenda das políticas públicas de esporte lazer no Brasil, com o objetivo de desenvolver o esporte de alto rendimento. A legitimação do futebol como secretaria única dentro da estrutura ministerial confirma o interesse do Estado brasileiro em atender as recomendaçôes da FIFA.

A Copa do Mundo FIFA 2014 teve como objetivo catalisar planos de investimentos para melhorar a infraestrutura e as condições de vida da sociedade. O governo brasileiro pretendeu melhorar diversos setores: Infraestrutura; Estádios; Segurança; Saúde; Meio ambiente e sustentabilidade; Desenvolvimento turístico; Promoção comercial e tecnológica; Cultura, educação e ação social; e Transparência ${ }^{34}$. 
O projeto Copa do Mundo FIFA 2014 apesar de ter apresentado no seu planejamento uma proposta de melhoria em diversos setores da sociedade, não deu garantias de um sistema que assegurasse essas melhorias e o maior beneficiado foi a entidade internacional. $\mathrm{O}$ argumento que a FIFA foi a maior beneficiada pode ser confirmado na Lei n. 12.663, de 5 de junho de 2012 (Lei Geral da Copa), capítulo 2, seção II, artigo $11^{\circ}$ :

A União colaborará com os Estados, o Distrito

Federal e os Municípios que sediarão os Eventos e com as demais autoridades competentes para assegurar à FIFA e às pessoas por ela indicadas a autorizaçáo para, com exclusividade, divulgar suas marcas, distribuir, vender, dar publicidade ou realizar propaganda de produtos e serviços, bem como outras atividades promocionais ou de comércio de rua, nos Locais Oficiais de Competição, nas suas imediaçôes e principais vias de acesso ${ }^{35}$.

Essa lei buscou atender a um projeto transnacional, de interesse privado, e garantiu exclusividade dos lucros para a FIFA, o que feriu outras leis conquistadas historicamente no Brasil, como o direito à liberdade de exercício da profissão, e contraria o Código de Defesa do Consumidor. Além disso, o projeto Copa do Mundo FIFA 2014 não partiu de uma demanda externa da sociedade civil, mas sim de uma demanda interna do Ministério do Esporte. A Lei Geral da Copa interfere ainda na Lei n. 10.671, de 15 de maio de 2003 (Lei Estatuto de Defesa do Torcedor), quando ocultou o artigo que proibia a venda de bebidas alcoólicas em estádios brasileiros, e permite a sua comercialização no período de competição.

A SNFDDT tem como responsabilidade o Estatuto de Defesa do Torcedor, que articulou o Ministério do Esporte, o Ministério da Justiça, o Conselho Nacional de Procuradores-Gerais do Ministério Público e a Confederação Brasileira de Futebol $(\mathrm{CBF})^{18}$. A partir do estatuto, os tumultos e violência nos estádios, cambismo e fraude nos resultados dos jogos se tornaram crimes, a partir do dia 27 de julho de $2010^{36}$.

REIs $^{37}$, ao realizar uma pesquisa acerca do Estatuto de Defesa do Torcedor, destacou que aproximadamente 50\% dos artigos e incisos da Lei n. 10.671, de 15 de maio de 2003, ainda não são cumpridos, situação pela qual o Ministério do Esporte, CBF e algumas entidades afiliadas são corresponsáveis. As principais responsabilidades relacionadas à infraestrutura são: garantir um acesso e uma saída para cada 1.000 espectadores em potencial; garantir estádios com no máximo 5.000 espectadores por setor; garantir que cada portão de entrada tenha uma câmera instalada para o monitoramento de imagens; garantir lanchonete e banheiros em cada setor conforme a lei.

O Estatuto de Defesa do Torcedor tem como objetivo analisar o cumprimento das normas de proteção e defesa do torcedor pelas autoridades responsáveis, garantindo a segurança e a prevenção da violência nos espetáculos de futebol. A lei corresponde a um marco para o exercício da cidadania no Brasil, obrigando os promotores de eventos esportivos a atenderem as suas normas. Vale ressaltar que o Estatuto de Defesa do Torcedor foi a primeira lei assinada para o esporte no governo de Luis Inácio Lula da Silva, do $\mathrm{PT}^{37}$.

A SNFDDT ainda tem como responsabilidade o projeto da loteria (Timemania), que foi sancionado a partir da Lei n. 11.345, de 14 de setembro de 2006. A distribuição da arrecadação segue os seguintes valores: $46 \%$ para o valor dos prêmios; $22 \%$ para os clubes que aderiram à loteria; $20 \%$ para o custeio e manutenção do serviço; 3\% para projetos esportivos na rede de educaçáo básica e superior e para ações dos clubes sociais; 3\% para o Fundo Penitenciário Nacional; 3\% para as Santas Casas de Misericórdia; 2\% para a Lei Agnelo/Piva; e $1 \%$ para a seguridade social ${ }^{38}$.

O projeto Timemania dispóe de uma ajuda dupla para os clubes pagarem impostos e contribuiçóes federais em atraso. As dívidas são financiadas, com a redução de juros e eliminação das multas por atraso, e para isso foi criada uma loteria que gerou uma receita extra aos clubes. No entanto, a lei foi centralizada em apenas 98 clubes dos mais de 400 afiliados a CBF em 2012, o que criou um desequilíbrio na distribuição dos recursos, além disso, os times com maiores torcidas foram os mais beneficiados, por terem mais apostadores, o que concentrou ao invés de distribuir. Em síntese, a lei buscou pagar a dívida dos clubes (setor privado) com os recursos do próprio credor (cidadão brasileiro), com as apostas na loteria Timemania, o que fortaleceu o setor privado, e se aproximou do modelo de gestão pública gerencial. No que se refere à análise da Secretaria Executiva, foi possível verificar que os projetos Praça da Juventude ${ }^{\mathrm{j}}$ e Praça do PAC ${ }^{\mathrm{k}}$ corresponderam às políticas públicas de modernização e construção de espaços e equipamentos de esporte, lazer e cultura.

No entanto, mais uma vez essa ação reafirma a aproximação do Ministério do Esporte com o modelo de gestão pública gerencial descrita por PAUlA $^{20}$, ao direcionar as praças para as áreas de vulnerabilidade social. O Estado, neste contexto, entra como o regulador para as classes mais baixas, 
e força as classes com maior acesso, a buscarem o esporte e o lazer no mercado.

Dessa forma, o Ministério do Esporte tem desenvolvido um modelo de gestão pública híbrida, como percebidos no PELC, se aproximando do modelo de gestão pública social, ao buscar o desenvolvimento de uma gestão com participação da sociedade civil. Ao mesmo tempo, o programa foi direcionado para as áreas de vulnerabilidade social, e se aproximou de uma gestão pública gerencial. Vale ressaltar que as açóes políticas do Ministério do Esporte tenderam a gestão pública gerencial, com foco na dimensão econômico-financeira e na busca dos resultados.

\section{O direito social ao lazer nas ações políticas do Ministério do Esporte}

Nessa segunda categoria de análise, foi discutida a compreensão do Ministério do Esporte acerca dos direitos sociais em suas açôes políticas. Os direitos sociais correspondem às garantias de participação da população na riqueza coletiva e respondem às necessidades humanas básicas. A garantia desses direitos envolve o bem-estar econômico mínimo, o direito a educação, a segurança, a habitação, a alimentação, ao trabalho, à saúde, ao lazer, dentre outros ${ }^{39}$.

No Estado brasileiro, o lazer passou a ser contemplado como direito social a partir da Constituição Federal de 1988, no entanto, não foi criado um sistema nacional que garantisse o mesmo como tal. Behring e Boschetti ${ }^{40}$ destacam dois modelos de políticas sociais, no contexto brasileiro, que compreendem os direitos sociais de forma distinta: as políticas sociais progressistas, orientadas pela ótica da materialização dos direitos de forma participativa e universal, buscando a desmercadorizaçáo dos serviços; e as políticas sociais neoliberais, orientadas pelo mercado, em busca da desresponsabilizaçáo dos direitos sociais, compreendidas como serviços a serem prestados pelo Estado. Esse modelo tem como ênfase a questão econômica e o Estado tem um papel de legislador e árbitro.

No primeiro setor analisado, a SNEAR, foi possível verificar que as políticas públicas buscaram o atendimento do acesso ao direito individual, uma vez que os benefícios foram direcionados apenas a um tipo de "público", formado pelos atletas de alto rendimento. Entre essas açóes, destaca-se o Programa Bolsa Atleta, que transfere os recursos financeiros do governo federal para os esportistas que alcançaram resultados significativos em âmbito nacional e internacional, com o intuito de melhorar a imagem do Estado.
O Programa Bolsa Atleta foi instituído a partir da Lei n. 10.891, de 9 de julho de 2004, e do Decreto n. 5.342, de 14 de janeiro de 2005. A bolsa varia de acordo com a categoria do atleta: Bolsa-Atleta Categoria Base e Bolsa-Atleta Categoria Estudantil recebem o valor mensal de R \$ 370,00; Bolsa-Atleta Categoria Nacional recebe R\$ 925,00; Bolsa-Atleta Categoria Internacional recebe R \$ 1.850,00; e Bolsa-Atleta Categoria Olímpico e Paralímpico recebem R \$3.100,00 ${ }^{41}$. Ao beneficiar apenas os atletas, o Ministério do Esporte não contempla o princípio básico das políticas públicas universalizantes e de acesso democrático, contemplando apenas os atletas que chegaram aos resultados expressivos, sem investimento na base esportiva.

$\mathrm{Na}$ segunda secretaria analisada, a SNEELIS, mereceram destaque os programas PELC e PST, que buscaram atender as práticas de esporte e lazer como direitos sociais. De acordo com SuAssuna et $\mathrm{al}^{42}$ e Castellani Filho ${ }^{3}$ a partir do PELC, o Ministério do Esporte passou a assegurar o incentivo financeiro às práticas de lazer com cunho esportivo, cultural e artístico, em prol do acesso democrático e inclusão social. O programa tem como princípio o reconhecimento do lazer como direito social e expressa a vontade da açáo governamental como resposta à necessidade social.

No entanto, a focalizaçáo do PELC "fere" o princípio da universalização do lazer como direito social, e cria uma contradiçáo entre o que foi previsto na Constituição Federal de 1988 (acesso universal) e o que foi proposto no programa (acesso focalizado). Essa focalização em um determinado público-alvo buscou aliviar as tensōes sociais, e cria um sistema de proteção social aos mais necessitados. Dessa forma, o modelo do PELC, forçou o modelo de mercado, à medida que compreendeu o lazer como uma mercadoria a ser comprada pelas classes mais altas, o que aproximou o programa das políticas sociais em um ambiente de aprofundamento do projeto político neoliberal, como descrito por BEHRING e BOSCHETTI ${ }^{40}$.

$\mathrm{Na}$ análise do PST, apesar do mesmo ser pautado no acesso ao direito social, foi verificado uma aproximação com as estratégias neoliberais. O PST compreende o esporte e o lazer como "serviços" e não como direitos sociais, focaliza as açóes nas pessoas e comunidades em situaçôes de vulnerabilidade social e garante um reforço alimentar ${ }^{24}$.

Acrescentam-se ainda como limites do PST o discurso salvacionista sobre as práticas esportivas; interesses e disputas políticas na implementação das açôes; e escassez de dados que permitem uma avaliação precisa quanto aos efeitos alcançados pelo 
programa relacionado à melhoria da qualidade de vida e acesso aos direitos sociais ${ }^{43}$.

Dessa forma, foi possível verificar que não existe indicativo que o Ministério do Esporte tem desenvolvido políticas sociais orientadas pela ótica da materialização dos direitos legalmente reconhecidos, conforme BEHRING e BoschetTi ${ }^{40}$. A partir da análise documental é possível afirmar que os cidadãos se mantiveram dependentes do mercado, já que não existe um programa que garanta, de forma universal, o acesso às práticas de esporte como forma de lazer. Existe apenas um discurso não efetivo, na prática, desde 2003, de criação de um Sistema Nacional de Esporte e Lazer.

É perceptível que o cidadão desejado pelo Ministério do Esporte corresponde ao cliente. O Estado oferece o serviço como bem a ser consumido, e cabe ao cidadão fiscalizá-lo. Na próxima sessão será aprofundado o modelo de participação da sociedade civil na gestão do Ministério do Esporte.

\section{Participação da sociedade civil na gestão pública do Ministério do Esporte}

A participação da sociedade civil no Brasil foi inserida dentro de contexto mais amplo na luta contra a ditadura militar, sobretudo com os movimentos sociais dos anos de 1960 e 1970. Esses movimentos foram marcados pela forte atuação dos sindicatos, associaçóes e partidos políticos na luta pela transformação da sociedade e alargamento da democracia. Nos anos de 1980 foi marcado um novo quadro da organização civil no país, à medida que superou tanto quantitativa quanto qualitativamente o conjunto de experiências participativas, o que fez ampliar e pluralizar os grupos, associaçóes e instituiçóes civis, que se posicionaram de forma autônoma em relação ao Estado ${ }^{44}$.

No entanto, a partir dos anos de 1990, com as constantes mudanças na sociedade e incorporaçáo do neoliberalismo, os movimentos sociais passaram a perder força e organização, sendo fragmentados e esvaziados. Nesse período ocorreu uma ressignificação da participação da sociedade civil, com a emergência da "participação solidária”, com ênfase na solidariedade, o que fez perder o sentido político e coletivo, o que promoveu a despolitização da participação. O Estado passa a construir novos canais de participação como os conselhos e conferências nacionais, estaduais e municipais ${ }^{43}$.

Com a criação do Ministério do Esporte, no ano de 2003, a participação da sociedade civil já se encontrava institucionalizada. Logo, "a priori”, pode-se afirmar que no caso das açóes políticas do Ministério do Esporte, não foi perceptível a participação da sociedade civil de forma movimentalista, por meio dos sindicatos e associações, como ocorreu nos anos de 1980, em busca do alargamento da democracia. Nos dados documentais coletados, foram verificados dois canais possíveis para ocorrer à participação: as CNEs e o Conselho Nacional de Esporte.

A CNE foi instituída pelo Decreto Presidencial, de 21 de janeiro de 2004, e se configura como um espaço de debate, formulação e deliberação das políticas públicas de esporte e lazer. Foram realizadas três conferências no Brasil: a I CNE em 2004; a II CNE em 2006; e a III CNE em 2010. Todas as $\mathrm{CNEs}$ ocorreram em três etapas, nas diferentes esferas de governo: municipal, estadual e federal ${ }^{45-47}$.

Averiguou-se que a I CNE, realizada em 2004, propôs como objetivo a criação de uma Política $\mathrm{Na}$ cional do Esporte e Lazer, e contemplou os campos como direitos sociais que interessam à sociedade, sendo passíveis de legitimação pelo Estado, ao qual cabe promover a sua democratização ${ }^{45}$.

O Ministério do Esporte em 2004, por meio da I CNE, compreendeu a sociedade civil como instância essencial para o desenvolvimento do esporte e do lazer, ao estabelecer como açóes fundamentais:

Realizar diagnóstico da estrutura esportiva e de lazer e propor açóes articuladas entre os diversos níveis da administraçáo pública e ou em articulaçáo com a iniciativa privada e organizaçóes da sociedade civil, para construção, modernização, revitalização, preservaçáo, otimização e maximização de espaços e equipamentos para o esporte e lazer com segurança e qualidade, visando o interesse e necessidades da população, contemplando a acessibilidade de pessoas com deficiência e pessoas com necessidades especiais, idosas e idosos, flexibilidade de horários e utilização, descentralização e desconcentração dos espaços e equipamentos públicos e privados, tais como escolas, passeios, parques, ginásios, entidades esportivas, sem fins lucrativos e/ou econômicos, estádios, creches e universidades, instituiçôes de longa permanência, priorizando comunidades com populaçóes em situação de vulnerabilidade ou exclusão social ${ }^{45}$.

Na II CNE, realizada em 2006, foi proposta uma nova estruturação do Sistema Nacional de Esporte e Lazer, com a intenção de unificar as açôes de desenvolvimento dos setores, cujo objetivo central foi consolidar os campos como direitos sociais, e continuar as conquistas da primeira edição realizada em 2004. A II CNE tem como marco a conquista 
da Lei de Incentivo ao Esporte e a qualificação do debate sobre as propostas apresentadas ${ }^{46}$.

A Lei n. 11.438, de 29 de dezembro de 2006 (Lei de Incentivo ao Esporte), foi criada a partir da II $\mathrm{CNE}$, com o intuito de estimular a prática esportiva, por meio da dedução fiscal de pessoas físicas e jurídicas. No capítulo I, artigo $1^{\mathrm{o}}$, foi abordado que as deduçôes de impostos ficam limitadas: I relativamente à pessoa jurídica, a $1 \%$ do imposto devido (Redaçáo dada pela Lei n. 11.472, de 2007); II - relativamente à pessoa física, a $6 \%$ do imposto devido na Declaração de Ajuste Anual ${ }^{48}$.

A lei tem indicativos de aproximaçáo com as estratégias neoliberais, à medida que transfere as responsabilidades do Estado em direção ao setor privado (pessoas jurídicas) e setor privado não lucrativo (pessoas físicas). O setor privado tem utilizado da dedução fiscal para a melhoria da imagem das empresas e instituições, em busca da obtenção indireta de lucro. Enquanto que o setor privado não lucrativo tem atuado na desobrigação do Estado e no desenvolvimento do esporte como prestação de serviço à sociedade, e não buscou uma atuação da sociedade civil no modelo de cogestão $\mathrm{O}^{48}$.

O documento final da II CNE definiu em plenária os seguintes objetivos para o Ministério do Esporte: Incentivar, apoiar e financiar políticas públicas descentralizadas e desconcentradas, que promovam a produçáo de conhecimento e estudos científicos visando o desenvolvimento do lazer, da Educação Física e do esporte em suas diversas manifestaçôes. Essas políticas deverão contemplar a iniciação científica, a criação e manutenção da infraestrutura e modernizaçáo de equipamentos para o desenvolvimento de centros, núcleos e grupos de pesquisa, preferencialmente em universidades ${ }^{46}$.

A participação na II CNE também foi indicada como princípio importante de gestáo e para a democratização das açóes políticas nos setores do esporte e do lazer. O Ministério do Esporte realizou ainda, em outubro de 2005, o I Fórum do Sistema Nacional de Esporte e Lazer, reunindo representantes do esporte nacional com experiências diferenciadas, e procurou contemplar o esporte em todas as suas dimensóes.

A partir da I e da II CNE foi possível afirmar que não existe um modelo social e político que reconheça o esporte e o lazer como direitos sociais, apenas um discurso falacioso que entende os mesmos como funcionais e remediadores de problemas sociais. As "Conferências" se configuraram como forma de descentralização das discussōes acerca das políticas públicas, no entanto, na prática ocorreu a centralizaçâo na tomada de decisóes. Na II CNE foi destacada uma possível desobrigação do Estado na garantia do direito ao lazer, e buscou transferir essa responsabilidade para esfera do mercado ${ }^{49}$, o que corroborou com os dados da segunda categoria discutida no presente artigo, quando foi apontado para o desenvolvimento dos direitos sociais em uma perspectiva neoliberal.

$\mathrm{Na}$ III CNE, no ano de 2010, foi elaborado o Plano Decenal do Esporte, que estabeleceu linhas estratégicas, açóes, metas e compromissos em prol do desenvolvimento do esporte. A conferência teve como objetivo tornar o país uma potência esportiva mundial, sendo que o tema central foi "Por um time chamado Brasil", já que o país foi sede da Copa do Mundo FIFA 2014 e vai ser sede dos Jogos Olímpicos Rio $2016^{47}$.

Ao elaborar o Plano Decenal do Esporte, na III CNE, foi visível a preocupação do Ministério do Esporte com o crescimento e desenvolvimento do esporte de alto rendimento, com o intuito de tornar o Brasil uma potência esportiva mundial. Nessa conferência, foi verificada uma fragilidade da participação da sociedade civil nas decisões políticas, que foi limitada à discussão, sem o poder de decisão. Além disso, as entidades da sociedade civil que participaram da discussão corroboraram para a afirmação da agenda dos megaeventos esportivos, como o CONFEF, CBF e COI. Essa discussáo dos megaeventos esportivos na etapa nacional só comprova o distanciamento entre o que foi debatido nas esferas municipais e estaduais, e o que foi proposto pelo governo federal na plenária final da etapa nacional.

Os documentos das CNEs apontam para uma política intersetorial e envolve os ministérios, as secretarias estaduais e municipais do esporte, saúde, educação, cultura, meio ambiente, turismo, dentre outras. Nas conferências são destacadas como ação intersetorial, o Sistema Nacional de Esporte e Lazer, tendo por base o regimento de colaboração entre Uniáo, estados, municípios e sociedade civil. No entanto, a participação da sociedade civil não tem conseguido distribuir o poder para os setores periféricos, uma vez que o processo decisório continua centralizado no Estado ${ }^{8}$.

No segundo canal de participação analisado, o Conselho Nacional de Esporte, foi verificado que sua criação ocorreu por meio do Decreto n. 4.201, de 18 de abril de 2002, com o objetivo de promover a atividade física para toda a populaçáo, bem como a melhoria da gestão, qualidade e transparência do esporte nacional ${ }^{50}$.

Apesar da sua criação em 2002, o Conselho Nacional do Esporte foi citado pela primeira vez na Lei n. 9.615, de 24 de março de 1988 , e foi alterado pela 
redação da Lei n. 10.672, de 15 de maio de 2003, quando estabeleceu no seu Art. 11 que: "O Conselho Nacional do Esporte é órgão colegiado de normatização, deliberação e assessoramento, diretamente vinculado ao Ministério de Estado do Esporte" ${ }^{21}$.

Dentre os principais objetivos do Conselho Nacional do Esporte, estão em destaque: oferecer subsídios técnicos à elaboração do Plano Nacional do Esporte; propor prioridades para o plano de aplicação de recursos do Ministério do Esporte; aprovar os Códigos de Justiça Desportiva e suas alterações, com as peculiaridades de cada modalidade; e expedir diretrizes para o controle de substâncias e métodos proibidos na prática esportiva. $\mathrm{O}$ conselho representa a criação de uma nova perspectiva para o esporte nacional ${ }^{51}$.

No entanto, essa participação por conselho foi dificultada pelo artigo 12 da Lei n. 10.672, de 15 de maio de 2003, quando foi proposto que "O Conselho Nacional do Esporte será composto por 22 membros indicados pelo Ministro do Esporte, que o presidirá" ${ }^{1}$. Essa indicação realizada pelo ministro, não deixa clara a porcentagem de representantes da sociedade civil que comporão esse canal de participação, o que tem gerado o enfraquecimento e desorganização da sociedade civil no setor.

Os conselhos, de acordo com PAula ${ }^{20}$ deve promover a participaçáo da sociedade civil em busca da democratização das açóes e decisóes políticas no setor, bem como captar financiamento para compor sua infraestrutura. No entanto, no caso do Ministério do Esporte, o funcionamento por indicação do ministro do esporte, não tem o poder de evitar o corporativismo.

$\mathrm{Na}$ atual configuração do contexto político do Ministério do Esporte, a participação da sociedade civil tem se restringido aos conselhos e as conferências, e são as únicas portas para a representação pública dos interesses dos setores populares. Vale ressaltar que a participação aqui defendida, não compreende a sociedade civil como "polo de virtude" e o Estado como "encarnação do mal”, conforme discutido por DAGNINO ${ }^{52}$.

A sociedade civil que concebemos não corresponde à panaceia para a resoluçáo de todos os problemas sociais, mas sim, um ator central da política no exercício da cidadania, em um modelo de Estado ampliado, democrático e igualitário. A participação da sociedade civil, nesse contexto, requer o exercício da cidadania, relacionada ao direito a ter direitos ${ }^{52}$.

Nos programas das outras secretarias, SNEAR e SNFDDT não foram descritas a participação da sociedade civil em suas açóes políticas. Apenas o PELC, alocado na SNEELIS, descreveu o incentivo ao controle social e a busca de participação local da comunidade, no entanto, essa participaçáo, como apresentados nos dados tendem ao aprofundamento do projeto político neoliberal, e busca compreender o cidadão como um parceiro, que deve assumir as responsabilidades do Estado ao fim do convênio. Além disso, não existem evidências que confirmem a participação da sociedade civil de forma democrática e participativa, compreendendo o cidadáo como centro do processo, o que mostra a falta de interesse do Estado em criar um repertório maior de canais, que possibilite a participação ativa da sociedade civil.

Como consideraçôes finais, podemos enfatizar que os objetivos pretendidos pelo artigo foram alcançados, à medida que foi realizada uma discussão panorâmica sobre as açóes políticas do Ministério do Esporte, o que garantiu uma originalidade e relevância para o estudo. Foi constatado um aumento de açóes políticas em esporte e lazer no Brasil, sobretudo após a criação do Ministério do Esporte em 2003 como pasta única governamental, quando foram verificadas duas correntes que atuaram na gestão pública: uma progressista e a outra conservadora.

No primeiro mandato do presidente Luís Inácio Lula da Silva, foi perceptível à atuação de uma corrente progressista, que criou programas com foco no esporte educacional (PST) e no esporte de participação (PELC), e buscou o acesso aos direitos sociais e a criação de um Sistema Nacional de Esporte e Lazer, conforme documentos finais da I CNE. No segundo mandato do presidente e início do mandato de Dilma Rousseff, o lazer tendeu a uma corrente mais conservadora, com a consolidação da agenda dos megaeventos esportivos. Além disso, houve uma tentativa de desobrigação do Estado da garantia dos direitos sociais, como verificado na criação da Lei de Incentivo ao Esporte e no debate da III CNE, o que reafirmou resultados de achados recentes e transcendeu na discussão acerca da gestão pública, direitos sociais e participação.

As açôes políticas do Ministério do Esporte, em síntese, compreenderam: o acesso a espaços e equipamentos de esporte e lazer, como percebidos no Projeto Praça da Juventude e Projeto PAC; a formação dos agentes sociais de esporte e lazer, como detalhado no PELC; e o atendimento as três dimensóes do esporte, com destaque para Jogos Escolares Brasileiros e PST na contemplação do esporte educacional, PELC e Rede Cedes, no atendimento do esporte de participação, e a Rede CENESP, o Programa Descoberta do Talento Esportivo, a Copa do Mundo FIFA 2014 e os Jogos Olímpicos Rio 2016, no atendimento do esporte de alto rendimento. 
O Ministério do Esporte tem desenvolvido uma gestão pública híbrida, com indicativos gerenciais e societais. Esse tipo de gestão pode ser justificado pelo contexto político brasileiro, que na década de 80 buscou o alargamento da democracia, e contemplou o lazer como um direito social a partir da Constituição Federal de 1988. No entanto, a criação do Ministério do Esporte em 2003, só ocorreu em um ambiente de avanço das estratégias neoliberais no país. Logo, as açôes políticas tenderam mais para um modelo de gestáo pública gerencial, com ênfase na dimensão econômica e na desobrigação do Estado da garantia do lazer como direito social.

Vale ressaltar que grande parte das açóes, projetos e programas desenvolvidos pelo Ministério do Esporte se configuraram como políticas sociais focalizadas, na tentativa da minimização das desigualdades, em contrapartida, não existem indicadores sociais que comprovem impactos sociais de minimização das desigualdades e acesso ao direito. Ao priorizar políticas sociais focalizadas, o Ministério do Esporte tem produzido o sujeito vulnerável, e cria um estigma de uma condição social, ou de sujeitos que necessitam da proteção social. As açóes políticas do Ministério do Esporte têm priorizado predominantemente jovens e adolescentes do gênero masculino e pertencentes às áreas de vulnerabilidade social. Esse aspecto merece ser investigado por novas pesquisas, que verifique se o Estado tem utilizado de técnicas de coerção com esse público, ao propor uma política de ocupaçáo do tempo livre.

Apontamos assim para necessidade de universalização da gestão das políticas públicas do Ministério do Esporte, que compreenda o lazer enquanto direito social, como contemplado em Constituição Federal de 1988. Chamamos a atenção para necessidade de ampliação dos debates com novas conferências para o setor, que aponte para a desmercadorização do lazer, bem como retornar ao objetivo inicial do Ministério do Esporte, de criação de uma Política Nacional de Esporte e Lazer de forma universal. Para isso, o modelo de gestão pública tem que avançar para além das questóes gerenciais, de eficiência e eficácia das açôes, e ampliar para um modelo mais societal, com a criação de canais de participação da sociedade civil.

Foi perceptível a falta de repertórios de participação da sociedade civil, existindo apenas dois canais de participação: as CNEs e o Conselho Nacional de Esporte. Ambos os canais, se apresentaram como frágeis, e não existe de fato uma participação efetiva na construção das açôes políticas do Ministério do Esporte.

\section{Notas}

a. O termo vulnerabilidade social tem sido utilizado pelos programas governamentais, significando o direcionamento de açóes ao um determinado público, com o intuito de conter a violência individual ou coletiva.

b. O Pintando a Liberdade acontece dentro do sistema penitenciário e oferece aos presos uma oportunidade de trabalho, por meio da confecção de materiais esportivos para utilização no PELC e PST. Os participantes têm a redução de um dia em sua pena a cada três dias trabalhados. Além disso, recebem salários, que são pagos em duas etapas: uma parte durante a pena e a outra fora da penitenciária ${ }^{53}$.

c. O Pintando a Cidadania foi criado a partir do Pintando a Liberdade. As unidades são instaladas em áreas de vulnerabilidade social, em conjunto com as lideranças locais e as Organizaçôes Não Governamentais (ONGs). A renda gerada deve ser dividida para cada trabalhador conforme a produção ${ }^{54}$.

d. Jogos dos Povos Indígenas correspondem ao maior encontro esportivo cultural e tradicional da América, idealizados por dois irmãos terenas (indígenas) representantes do Comitê Intertribal - Memória e Ciência Indígena ${ }^{55}$.

e. Usamos esta expressão por entendermos que o lazer abrange manifestaçóes esportivas, mas também artísticas, culturais e turísticas.

f. Em 2011, a parceria entre o Programa Nacional de Segurança Pública com Cidadania (Pronasci) (Ministério da Justiça) e o PELC se desfez. O Pronasci foi criado pela Lei n. 11.530, de 25 de outubro de 2007, e sua associação com o PELC teve como base criadora os relatórios de Segurança Pública, os quais mostram que as taxas mais altas de homicídio são registradas nas regióes metropolitanas, em que a pobreza, desemprego e acesso aos direitos são precários.

g. Os Jogos da Juventude data de 1995 e representa a base do desenvolvimento do setor na tentativa da descoberta de novos talentos esportivos na rede pública ou particular de ensino.

h. As Olímpiadas Escolares envolvem oito modalidades: futsal, handebol, vôlei, basquete, atletismo, natação, judô, tênisde-mesa e xadrez. A partir de 2005 as Olimpíadas Escolares passaram a ser realizadas em duas fases: a primeira entre adolescentes de 12 a 14 anos de idade e a segunda com adolescentes entre 15 e 17 anos de idade. 
i. O JUBs no Brasil pode ser dividido em quatro etapas: a) a primeira fase foi iniciada em 1916 e envolvia apenas os universitários do Rio de Janeiro e São Paulo; b) a segunda fase do JUBs deu-se em 1941, quando o Estado passou a investir no esporte universitário; c) a terceira fase foi iniciada na década de 80, com a separaçáo entre esporte amador e profissional e perdurou até a década de 90 , quando o JUBs começou a ser utilizado como lucro financeiro; e d) a quarta fase e atual foi iniciada em 2004, quando o esporte adquiriu "status" de Ministério, optando por um modelo híbrido de gestão, envolvendo o CBDU, COB, além do incentivo as parcerias entre o setor público e privado ${ }^{56}$.

j. A Praça da Juventude deve abranger uma quadra poliesportiva coberta, pistas de corrida e caminhada (salto triplo, salto a distância), campo de futebol, quadra de vôlei de praia, pista de "skate", teatro, área de ginástica e centros de convivência geral e da terceira idade. As praças são classificadas como veículo para a democratização dos espaços e equipamentos para a prática de esporte e lazer, em parceria com o Ministério da Justiça. Cada praça custa em média R \$ 1,7 milhão ${ }^{57}$.

k. São três modelos de praças do PAC: 1) Praça de $700 \mathrm{~m}^{2}$ (praça coberta; pista de "skate"; equipamentos de ginástica; Centro de Referência de Assistência Social (CRAS); salas de aula; salas de oficina; telecentro; sala de reunião, biblioteca; cineteatro/auditório com 48 lugares, e terraço); 2) Praça de $3.000 \mathrm{~m}^{2}$ (CRAS); salas multiuso; biblioteca; telecentro; cineteatro/auditório com 60 lugares; quadra poliesportiva coberta; pista de "skate"; equipamentos de ginástica; "playground" e pista de caminhada); e 3) Praça de 7.000 m² (CRAS; salas multiuso; biblioteca com telecentro; cineteatro com 125 lugares; pista de "skate", equipamentos de ginástica; playground; quadra poliesportiva coberta; quadra de areia; jogos de mesa e pista de caminhada $)^{58}$.

\begin{abstract}
Management of public policies of the Ministry of Sport in Brazil

The purpose of this article was to discuss the political actions of the Ministry of Sports in the fields of sports and leisure. For this purpose, a document research was performed, followed by analysis of the content of legislation and documents that govern the policies of the Ministry of Sports. Three main categories emerged in this analysis: management model, concept of social law and channels of participation. The results indicated that public policies the political actions approach managerial public management, considering social rights as services to be rendered by the State. Furthermore, the participation of civil society only occurred in an institutionalized manner through the National Council of Sport and the National Conferences of Sport (CNEs -Conferências Nacionais de Esporte). Ambiguously, actions were also identified that promoted a societal view, expanding the understanding of leisure and affirming it as a social right. However, in recent years these actions have been subsumed by the managerial view.
\end{abstract}

KEY WoRDS: Leisure; Sport; Social rights; Participation.

\title{
Referências
}

1. Brasil. Constituição [da] República Federativa do Brasil. Brasília: Senado Federal; 1988.

2. Dagnino E. Sociedade civil, participação e cidadania: de que estamos falando? In: Mato D, organizador. Políticas de ciudadanía y sociedad civil en tiempos de globalización. Caracas: FaCes/Universidad de Venezuela; 2004. p.95-111.

3. Castellani Filho L, editor. Gestão pública e política de lazer: a formação de agentes sociais. Campinas: Autores Associados; 2007.

4. Reis LJA, Starepravo FA. Políticas públicas para o lazer: pontos de vista de alguns teóricos do lazer no Brasil. Licere. 2008;11:1-20.

5. Marcellino NC, editor. Lazer: formação e atuação profissional. 8a ed. Campinas: Papirus; 2007. v.1.

6. Bonalume CRO. Esporte e o lazer na formulaçấo de uma política pública intersetorial para a juventude: a experiência do PRONASCI [dissertação]. Brasília (DF): Universidade de Brasília, Faculdade de Educação Física; 2010. 
7. Bonalume CRO. O Paradigma da intersetorialidade nas políticas públicas de esporte e lazer. Licere. 2011;14:1-26.

8. Benedicto DBM. Desafiando o coro dos contentes: vozes dissonantes no processo de implementação dos Jogos PanAmericanos Rio 2007. Esporte Soc. 2009;4:1-29.

9. Melo MP. Organismos internacionais e grandes eventos esportivos: novas dinâmicas da dominação burguesa para o século XXI. Motrivivência. 2009;32/33:28-48.

10.Richardson RJ, Peres JAS, Wanderley JCV, Correia LM, Peres MHM. Pesquisa social: métodos e técnicas. São Paulo: Atlas; 1999.

11. Bardin, L. Análise de conteúdo. 4a ed. Lisboa: Ediçóes 70; 2009.

12. Brasil. Lei n. 10.683, de 28 de maio de 2003. Dispóe sobre a organização da Presidência da República e dos Ministérios, e dá outras providências. Diário Oficial da União, Brasília (29 mai. 2003); Sec.1:2.

13. Brasil. Decreto n. 4.668, de 9 abril de 2003. Aprova a estrutura regimental e o quadro demonstrativo dos cargos em comissão e das funçôes gratificadas do Ministério do Esporte. Diário Oficial da União, Brasília (10 abr. 2003); Sec.1:2.

14. Castelan LP. As conferências nacionais do esporte na configuração da política esportiva e de lazer no governo Lula (2003-2010) [dissertação]. Campinas (SP): Universidade Estadual de Campinas; 2010.

15. Tubino MJG. O esporte no Brasil, do período colonial aos nossos dias. São Paulo: Ibrasa; 1996.

16. Brasil. Decreto n. 7.529, de 21 julho de 2011. Aprova a estrutura regimental e o quadro demonstrativo dos cargos em comissão e das funçôes gratificadas do Ministério do Esporte. Diário Oficial da União, Brasília (22 jul. 2011); Sec.1:5.

17. Brasil. Ministério do Esporte. [Internet]. Organograma. [citado 20 dez 2011]. Disponível em: http://www.esporte.gov.br/.

18. Brasil. Decreto n. 7.784, de 7 de agosto de 2012. Aprova a estrutura regimental e o quadro demonstrativo dos cargos em comissão e das funçôes gratificadas do Ministério do Esporte. Diário Oficial da União, Brasília (8 ago. 2012); Sec.1:50.

19. Senado Federal. Ministério do Esporte. Siga Brasil. [citado 28 dez 2012]. Disponível em: http://www9.senado.gov.br/ portal/page/portal/orcamento_senado/SigaBrasil.

20. Paula APP. Por uma nova gestáo pública. Rio de Janeiro: FGV; 2005.

21. Brasil. Ministério do Esporte. Manual de orientação do programa esporte e lazer da cidade. Brasília: Secretaria Nacional de Desenvolvimento do Esporte e Lazer; 2004.

22. Brasil. Ministério do Esporte. Programa esporte e lazer da cidade: diretrizes. Brasília: Secretaria Nacional de Esporte, Educação, Lazer e Inclusão Social; 2012.

23. Ramos MLBC, editor. Política intersetorial: PELC e PRONASCI. Brasília: Fields; 2011. v.1.

24. Draibe S. As políticas sociais e o neoliberalismo: reflexôes suscitadas pelas experiências latino-americanas: dossiê liberalismo, neoliberalismo. Rev USP. 1993;17:86-101.

25. Starepravo FA, et al. E assim criou-se a rede: aspectos técnicos, políticos e epistemológicos envolvidos na criação e desenvolvimento da Rede Cedes. Movimento. 2014;20:33-58.

26. Brasil. Ministério do Esporte. Rede Cedes. [citado 7 jan 2012]. Disponível em: www.esporte.gov.br.

27. Brasil. Ministério do Esporte. Portaria n. 219, de 23 de dezembro de 2011. Chamada pública para seleção de projetos de pesquisa a serem desenvolvidos na REDE CEDES. Diário Oficial da União, Brasília (26 dez. 2011);Sec.1:303.

28. Brasil. Ministério do Esporte. Prêmio Brasil de esporte e lazer de inclusão social. [citado 7 jan 2012]. Disponível em: www.esporte.gov.br.

29. Brasil. Ministério do Esporte. Diretrizes do Programa Segundo Tempo 2011. Brasília: ME; 2011.

30. Brasil. Ministério do Esporte. Cartilha do Programa Descoberta do Talento Esportivo. Brasília: ME; 2004.

31. Brasil. Ministério da Educação. B 823 e Secretaria de Educação Física e Desportos. Esporte na escola: os XVIII jogos escolares brasileiros como marco reflexivo. Brasília: MEC/SEED; 1989.

32. Bracht, V. Sociologia crítica do esporte: uma introduçáo. 2a ed. Ijui: Unijui; 2003. v.1.

33. Brasil. Rio 2016: cidade candidata - dossiê de candidatura. Rio de Janeiro: COB; 2009. v.1.

34. Brasil. Ministério do Esporte. Balanço da Copa Mundo FIFA de 2014. Brasília: ME; 2011.

35. Brasil. Lei n. 12.663, de 5 de junho de 2012. Dispóe sobre as medidas relativas à Copa das Confederaçóes FIFA 2013, à Copa do Mundo FIFA 2014 e à Jornada Mundial da Juventude - 2013, que serâo realizadas no Brasil; altera as Leis n. 6.815, de 19 de agosto de 1980, e n.10.671, de 15 de maio de 2003; e estabelece concessão de prêmio e de auxílio especial mensal aos jogadores das seleçóes campeãs do mundo em 1958, 1962 e 1970. Diário Oficial da União, Brasília (6 jun. 2012); Sec;1:3.

36. Brasil. Lei n. 10.671, de 15 de maio de 2003. Dispóe sobre o Estatuto de Defesa do Torcedor e dá outras providências. Diário Oficial da União, Brasília (16 mai. 2003); Sec.1:1.

37. Reis HHB. O espetáculo futebolístico e o estatuto de defesa do torcedor. Rev Bras Ciênc Esporte. 2010;31:111-30. 
38. Brasil. Lei n. 11.345, de 14 de setembro de 2006. Dispóe sobre a instituição de concurso de prognóstico destinado ao desenvolvimento da prática desportiva, a participação de entidades desportivas da modalidade futebol nesse concurso e o parcelamento de débitos tributários e para com o Fundo de Garantia do Tempo de Serviço - FGTS. Diário Oficial da União, Brasília (15 set. 2006); Sec.1:1.

39. Carvalho JM. Cidadania no Brasil: o longo caminho. 10a ed. Rio de Janeiro: Civilização Brasileira; 2008.

40. Behring ER, Boschetti I. Política social: fundamentos e história. 8a ed. São Paulo: Cortez; 2011.

41. Brasil. Lei n. 10.891, de 9 de Julho de 2004. Institui a bolsa-atleta. Diário Oficial da União, Brasília (12 jul. 2004); Sec.1:1.

42. Suassuna D, Almeida AJM, Freire JO, Roquete PC. O Ministério do Esporte e a definição de políticas para o esporte e lazer. In: Suassuna DMFA, Azevedo AA, organizadores. Política e lazer: interfaces e perspectivas. Brasília: Thesaurus; 2007. v.1, p.13-42.

43. Athayde PFA. Programa Segundo Tempo: conceitos, gestão e efeitos [dissertação]. Brasília (DF): Universidade de Brasília, Faculdade de Educação Física; 2010.

44. Dagnino E. Os movimentos sociais e a construção democrática: sociedade civil, espaços públicos e gestão participativa. Idéias. 2000;2:7-96.

45. Brasil. I Conferência Nacional do Esporte: documento final. Brasília: Ministério do Esporte; 2004.

46. Brasil. II Conferência Nacional do Esporte: documento final. Brasília: Ministério do Esporte; 2006.

47. Brasil. III Conferência Nacional do Esporte: texto básico. Brasília: Ministério do Esporte; 2010.

48. Brasil. Lei n. 11.438, de 29 de dezembro de 2006. Dispóe sobre incentivos e benefícios para fomentar as atividades de caráter desportivo e dá outras providências. Diário Oficial da União, Brasília (29 dez. 2006); Sec.1:1.

49. Terra AM, Mascarenhas F, Flausino M, Bittar AJ. As Conferências Nacionais do Esporte: avanços e limites na construção das políticas de Esporte e Lazer. 16o Congresso Brasileiro de Ciência do Esporte e III Congresso Internacional de Ciências do Esporte; 20 set-25 2009; Salvador, BR. Salvador: CBCE: 2009, p.1-11.

50. Brasil. Ministério do Esporte. Portaria n. 221, de 1 de outubro de 2002. Credenciamento à Rede CENESP. Diário Oficial da União, Brasília (2 out. 2002); Sec.1:62.

51. Brasil. Lei n. 10.672, de 15 de maio de 2003. Altera dispositivos da Lei n. 9.615, de 24 de março de 1998, e dá outras providências. Diário Oficial da União, Brasília (16 mai. 2003); Sec.1:3.

52. Dagnino E, editor. Sociedade civil e espaços públicos no Brasil. São Paulo: Paz e Terra; 2002.

53. Brasil. Ministério do Esporte. Manual do Programa Pintando a Liberdade. [citado 6 jan 2012]. Brasília: ME: s.d. Disponível em: www.esporte.gov.br.

54. Brasil. Ministério do Esporte. Manual do Programa Pintando a Cidadania. Brasília: ME; s.d. [citado 7 jan 2012]. Disponível em: www.esporte.gov.br.

55. Brasil. Ministério do Esporte. Jogos dos povos indígenas. Brasília: ME; s.d. [citado 7 jan 2012]. Disponível em: www. esporte.gov.br.

56. Starepravo FA, Reis LJA, Mezzadri FM, Marchi Junior W. Esporte universitário brasileiro: uma leitura a partir de suas relaçóes com o Estado. Rev Bras Ciên Esporte. 2010;31:131-48.

57. Brasil. Ministério do Esporte. Manual para elaboração de projetos de implantação para construção das Praças da Juventude. Brasília: ME; 2010.

58. Brasil. Manual de Instruções para Seleção das Praças do PAC. Brasília: ME; 2010.

ENDEREÇO

Dirceu Santos Silva

Departamento de Educação Física e Humanidades

Faculdade de Educação Física

Universidade Estadual de Campinas

R. Érico Veríssimo, 701

13083-851 - Campinas - SP - BRASIL e-mail: dirceu_09@yahoo.com.br
Recebido para publicação: 30/04/2013

1a. Revisão: 09/03/2014

2a. Revisão: 16/10/2014

Aceito: 17/10/2014 